\title{
Pollution Maintenance Techniques in Coastal High Voltage Installations
}

\author{
K. Siderakis \\ Dept of EE \\ TEI of Crete \\ Heraklio, Greece \\ ksiderakis@stef.teicrete.gr
}

\author{
D. Pylarinos \\ Dept of ECE \\ University of Patras \\ Patras, Greece
}

\author{
E. Thalassinakis \\ Assistant Director \\ P.P.C. \\ Heraklion, Greece
}

\author{
I. Vitellas \\ Director \\ P.P.C. \\ Athens, Greece
}

\author{
E. Pyrgioti \\ Dept of ECE \\ University of \\ Patras \\ Patras, Greece
}

\begin{abstract}
Pollution of outdoor high voltage insulators is a common problem for utilities, with a considerable impact to power system reliability. In an effort to prevent possible flashovers due to pollution, many methods have been applied, aiming to improve the insulation performance, either by suppressing the formation of surface conductivity or by increasing the possible insulation level. In the case of substations, the selection of the appropriate technique is complex due to certain issues correlated to the nature of the installation. In this paper, several techniques usually implemented by utilities, are investigated based on the experienced gained in the case of Crete, a Greek island in southern Europe, where due to the coastal development of the power system, the majority of high voltage installations are exposed to intense marine pollution. The technique of coating insulators with Room Temperature Vulcanized Silicone Rubber (RTV SIR) has proved rather efficient and therefore is presented extendedly. Correlation of the material behaviour with environmental conditions is discussed and results from long term monitoring, including environmental parameters and leakage current measurements, in a $150 \mathrm{kV}$ Substation are presented. It is shown that RTV SIR coatings have remarkably suppressed surface activity and that porcelain insulators exhibit different activity period when coated.
\end{abstract}

Keywords: Pollution; RTV SIR; GIS; Substation; insulators; leakage current;

\section{INTRODUCTION}

A possible outage in a high voltage substation usually corresponds to a severe impact to the power system [1]. Therefore, from the reliability point of view, substation maintenance has a considerable importance, which increases with the corresponding increase of the correlated transmission circuits' number. Pollution of high voltage insulators is a problem experienced by many utilities worldwide. It originates from the environment and is capable of deteriorating the performance of outdoor insulation, under the nominal voltage stress.

The first step of the pollution phenomenon is the accumulation of contaminants on the insulation surface [2]. In the case of hydrophilic insulation (e.g. porcelain), the presence of a wetting mechanism (e.g. rain, fog, humidity) transforms the contaminants layer into a conductive film which permits the flow of leakage current through it. The flow of current heats up the surface and localized changes in the surface conductivity occur. Areas of higher resistance are formed, called dry bands, and discharges may appear (dry band arcs) which can ultimately lead to a complete flashover of the insulator [2]. Several methods have been applied to cope with the pollution problem [2-4]. The most usual suppressing method is the cleaning of insulators. Other methods employ different insulator and substationsdesign. Polymer insulators and coatings can also be employed in order to prevent film formation, by retaining moisture in the form of droplets. However, periods of hydrophobicity loss and recovery are observed [5-8]. In addition, discharges may appear from and between scattered water droplets. One of the polymer materials frequently used as coating is the Room Temperature Vulcanized Silicone Rubber (RTV SIR).

The power system in the Greek island of Crete suffers from intense pollution problems due to sea influence [9]. Several techniques have been employed from the Greek Public Power Corporation (PPC) to cope with the problem [10]. In this paper a brief description of substation pollution maintenance techniques that have been employed in the power system of Crete is presented. Further, the use of RTV SIR coatings is thoroughly investigated since a large scale application of such coatings has been issued by PPC in the Cretan Power Systems. In addition, data from a field leakage current monitoring system that has been installed in a $150 \mathrm{kV}$ Substation are presented and the performance of coated insulators is further investigated.

\section{THE POLLUTION PROBLEM WITHIN THE DESIGN}

Several methods can be applied to suppress the influence of the pollution phenomenon. The aspects usually considered within the design process are presented in Table 1 . The first step is the selection of the insulation's parameters. Usually, the leakage distance is the first parameter evaluated. The required value can be determined according to IEC60815, depending on 
the experienced problem intensity. However, the insulator geometry is also considerably important. An appropriate profile selection must take advantage of the self cleaning mechanisms present. Otherwise, problems may be experienced, although the leakage distance criterion is satisfied. Such a case has been experienced in Crete and is presented in [11]. The use of composite insulators that provide a hydrophobic surface is also a considered improvement. However the material lifetime is an issue, considering the replacement cost and availability. Further, the insulator geometry of the new insulators has to be evaluated. Maintenance ability is an added issue. Especially if live water washing is not possible, e.g. prohibited by law as in the case of Greece, different substation schemes must be employed, in order to avoid power interrupts and thus maintain high levels of quality. The scheme usually implemented contains multiple bus systems and sectionalizing circuit breakers.

TABLE I. DESIGN REMEDIES IN THE CASE OF NEW SUBSTATIONS

\begin{tabular}{|c|c|c|c|}
\hline & Design guideline & $\begin{array}{l}\text { Problem } \\
\text { intensity }\end{array}$ & Comments \\
\hline \multirow{3}{*}{$\begin{array}{l}\text { Insulator } \\
\text { selection }\end{array}$} & Leakage distance & Low & IEC60815 \\
\hline & Geometry & Low & $\begin{array}{l}\text { Physical cleaning } \\
\text { mechanisms }\end{array}$ \\
\hline & Material & Medium & $\begin{array}{l}\text { Hydrophobicity } \\
\text { Resistive glazed }\end{array}$ \\
\hline $\begin{array}{l}\text { Substation } \\
\text { scheme }\end{array}$ & $\begin{array}{l}\text { Multiple bus } \\
\text { systems } \\
\text { Sectionalizing } \\
\text { CBs or isolators } \\
\text { Automatic } \\
\text { washing systems }\end{array}$ & Medium & $\begin{array}{l}\text { Capability of live } \\
\text { washing }\end{array}$ \\
\hline \multirow{3}{*}{$\begin{array}{c}\text { Enclosed } \\
\text { substations }\end{array}$} & $\begin{array}{l}\text { Partially enclosed } \\
\text { in air }\end{array}$ & Increased & $\begin{array}{l}\text { Medium voltage } \\
\text { side }\end{array}$ \\
\hline & $\begin{array}{l}\text { Fully rnclosed in } \\
\text { air }\end{array}$ & Increased & $\begin{array}{l}\text { Both MV and HV } \\
\text { side }\end{array}$ \\
\hline & $\begin{array}{l}\text { Fully enclosed in } \\
\text { SF6 (gas insulated } \\
\text { systems) }\end{array}$ & Extreme & $\begin{array}{l}\text { Sophisticated } \\
\text { systems, } \\
\text { maintenance, cost }\end{array}$ \\
\hline
\end{tabular}

If severe pollution problems are due to appear, then the construction of enclosed substations can also be considered. In the case of Crete, the majority of the $150 \mathrm{kV} / 20 \mathrm{kV}$ substations are partially enclosed, with only the $150 \mathrm{kV}$ side exposed to the environment. In addition there is one $66 \mathrm{kV}$ air insulated substation that is fully enclosed, a view of which is illustrated in Figure 1. In both cases, the environment oriented problems are suppressed, however a control of the inner atmosphere is necessary considering that phenomena such as condensation may appear. The substation scheme that totally encounters pollution problems is a GIS installation, a substation enclosed in SF6. In this case the possibility of a pollution related problem is totally eliminated and the save of space achieved is an added considerable advantage. However there are issues to consider, concerning the maintenance means and procedures and the installation cost. In Crete at the moment there are two GIS $150 \mathrm{kV}$ substations. A picture of the $150 \mathrm{kV}$ GIS substation located in Heraklion is shown in Figure 2.

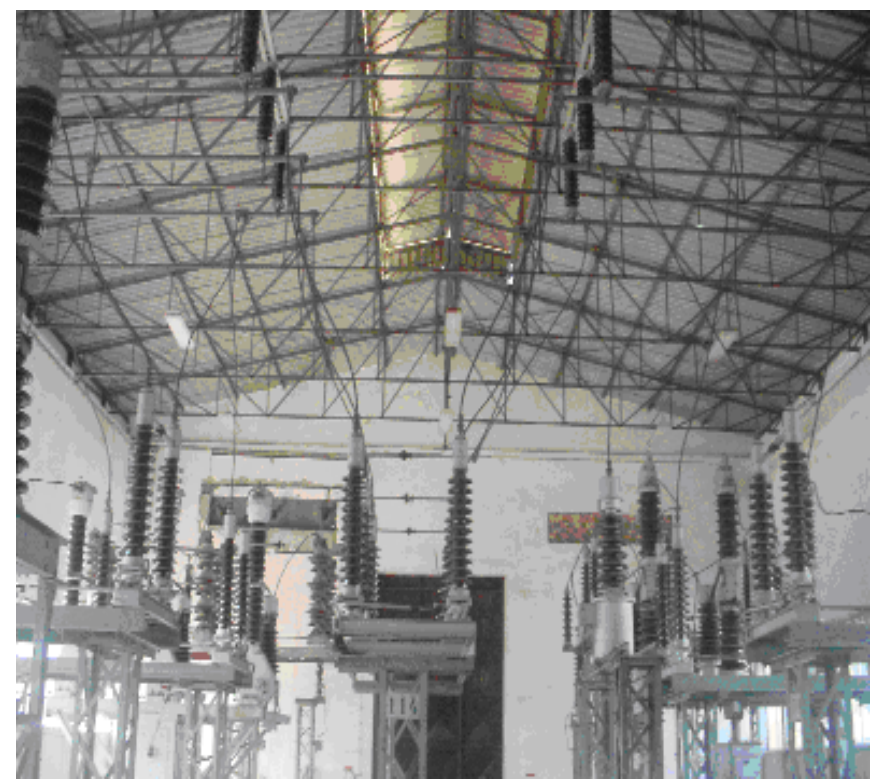

Figure 1. View of the $66 \mathrm{kV}$ enclosed air substation at Linoperamata

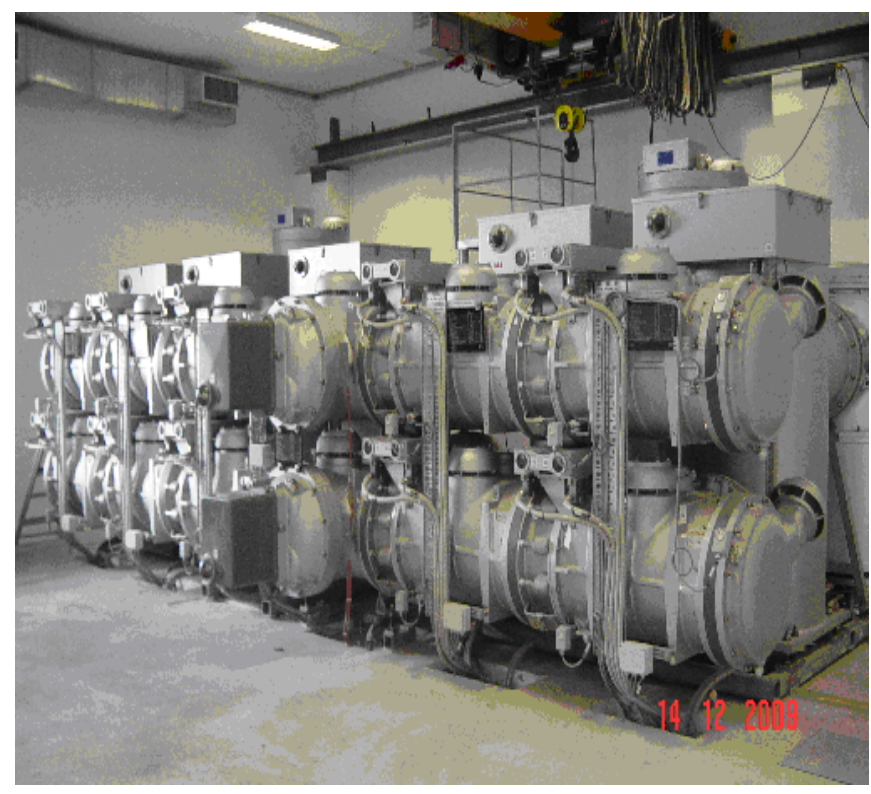

Figure 2. View of the $150 \mathrm{kV}$ GIS at Heraklion Crete

\section{POLLUTION MAINTENANCE METHODS IN SUBSTATIONS}

In the case of the already installed equipment, the financial investment required in order to apply any of the remedies reported in Table 1 is considerable. Therefore, to improve the performance of existing insulators, cleaning and coating application are usually employed. A sum of the pollution maintenance methods usually employed in the case of substations is presented in Table 2 . 
TABLE II. MAINTENANCE METHODS IN THE CASE OF SUBSTATIONS

\begin{tabular}{|c|c|c|c|}
\hline & $\begin{array}{l}\text { Maintenance } \\
\text { method }\end{array}$ & $\begin{array}{l}\text { Problem } \\
\text { intensity }\end{array}$ & Comments \\
\hline $\begin{array}{c}\text { Insulator } \\
\text { washing }\end{array}$ & $\begin{array}{c}\text { Automatic or } \\
\text { manual } \\
\text { systems }\end{array}$ & Any & $\begin{array}{l}\text { Live washing? } \\
\text { Time of washing } \\
\text { Work hours } \\
\text { Cost if power } \\
\text { interruptions are } \\
\text { required }\end{array}$ \\
\hline \multirow[t]{2}{*}{$\begin{array}{c}\text { Insulator } \\
\text { coatings }\end{array}$} & Silicone grease & Medium & $\begin{array}{l}\text { Method of preventive } \\
\text { maintenance } \\
\text { Limited lifetime } \\
\text { (encapsulation) } \\
\text { Necessary coating } \\
\text { replacement } \\
\text { Power interruptions } \\
\text { required } \\
\text { Work hours }\end{array}$ \\
\hline & RTV SIR & Medium & $\begin{array}{l}\text { Method of preventive } \\
\text { maintenance } \\
\text { Extended lifetime } \\
\text { (hydrophobicity) } \\
\text { Aging and } \\
\text { replacement are } \\
\text { issues }\end{array}$ \\
\hline $\begin{array}{l}\text { Creepage } \\
\text { extenders }\end{array}$ & Elastomeric & High & $\begin{array}{l}\text { Method of preventive } \\
\text { maintenance } \\
\text { Specific design for } \\
\text { each insulator } \\
\text { geometry } \\
\text { Application cost }\end{array}$ \\
\hline
\end{tabular}

\section{A. Cleaning and washing of insulators}

There are many different cleaning methods, and one has to consider parameters such as the number of insulators to be cleaned, the pollutant type, the possible by-products and the corresponding application cost in order to select the most appropriate in each case. The most common methods are summarized in Table 3 . The main problem concerning all methods included in Table 3 is the selection of the optimum cleaning time. This is an exclusively experience oriented parameter, which depends on various factors regarding the local service conditions. If cleaning is performed earlier than required then a critical build up of contaminants is possible to develop in short time which means that the problem reappears quickly. On the other hand the more the cleaning is delayed, the higher the possibility of an outage due to pollution. Further, there is a considerable financial cost related to the cleaning procedures, especially if they cannot be applied on live equipment. In the latter case a supply interruption is required, which corresponds to a deterioration of system reliability, since a part of a substation is set out of service and to an additional financial loss since it may be required to interrupt the power supply to a number of consumers. It is worth mentioning that this financial loss can be increased in the case of step up substations, if one or more power units are put out of operation for some hours, due to the supply interruption. The probable problems related to the power units operation can result to a significant additional cost [12].
TABLE III. INSULATOR CLEANING METHODS

\begin{tabular}{|c|c|c|c|}
\hline & $\begin{array}{r}\text { Cleaning } \\
\text { method }\end{array}$ & Deposit & \multicolumn{1}{c|}{ Comments } \\
\hline $\begin{array}{c}\text { Insulator } \\
\text { washing }\end{array}$ & $\begin{array}{c}\text { High } \\
\text { pressure } \\
\text { washing }\end{array}$ & $\begin{array}{c}\text { Deposits } \\
\text { with poor } \\
\text { adhesion }\end{array}$ & $\begin{array}{l}\text { Time of washing } \\
\text { Live washing? } \\
\text { Work hours } \\
\text { Cost if power } \\
\text { interruptions are } \\
\text { required }\end{array}$ \\
\hline $\begin{array}{c}\text { Insulator } \\
\text { cleaning }\end{array}$ & $\begin{array}{c}\text { Dry } \\
\text { cleaning }\end{array}$ & $\begin{array}{l}\text { Time of cleaning } \\
\text { Cement material deposits } \\
\text { Fertilizers }\end{array}$ & $\begin{array}{l}\text { Cost } \\
\text { Glaze damage and } \\
\text { insulator shattering }\end{array}$ \\
\hline
\end{tabular}

Consequently, insulator cleaning is a method that can be applied in order to ensure the insulation performance under pollution conditions, but there are two significant parameters that must be considered. The first is the selection of the optimum cleaning time, since it is a suppressive method (not preventive) and the second is the correlated financial cost, especially if live washing cannot be applied.

\section{B. Coating application}

Different types of coatings are provided by various manufacturers, however the two types mainly used in the industry, are Silicone Grease and RTV Silicone Rubber coatings [13]. The improvement achieved is the application of a preventive method (instead of a suppressing one), since the coating can be installed at a time convenient for the utility and within its operational lifetime is capable of suppressing the pollution influence at any time. In both cases, the phenomenon suppression is possible by providing a water repellant surface, which as a result does not permit the formation of a conductive film on the insulator's surface. The difference between the two types is the method employed in order to maintain the water repellency feature.

In the case of Silicone Grease, the deposited contamination is encapsulated within the material volume and as a result the surface is kept hydrophobic. This means that there is a saturation point, when the maximum contaminants amount that can be encapsulated is achieved. At this point the end of the coating service lifetime is achieved and the material must be removed. Otherwise, a performance even worse than an insulator without Silicone Grease, is probable to be experienced [13]. In the case of Crete, the average lifetime of silicone grease coatings is six months. Therefore, such a coating must be applied and further removed twice each year, something that limits a possible large scale application and it may only be applied on critical equipment. This limited coating service lifetime and the required man-hours for replacing the coating are the two primary drawbacks that limit the possible use of Silicone Grease.

In the case of RTV SIR Coatings, a hydrophobicity transfer capability is present, sufficient to change the initial hydrophilic behavior of the deposited contamination to hydrophobic [1418]. As a result, although the deposited contaminants remain on 
the surface (no encapsulation), the surface behavior is hydrophobic, suppressing the phenomenon development. This is a considerable improvement in comparison to Silicone Grease, since the accumulated contamination is still exposed to various cleaning mechanisms such as rain and therefore there is no saturation behavior. Further the application lifetime is elongated and can exceed a period of 5 years, achieving in some cases a lifetime of more than 10 years. Therefore, RTV SIR Coatings can be considered as a preventive measure that can provide an efficient solution in the case of substations. They can be applied on any insulator type, regardless of material, use and geometry. The application can take place at a time convenient for the utility and remain active for a period that most of the times exceed 5 years.

Certain concerns have to be answered in the case of application of RTV SIR coatings, like material aging, maintenance, optimum time of replacement and the corresponding cost (labour and financial). However, the preventive feature and the large scale application capability are considerable advantages that distinguish this method from the rest.

\section{Creepage Extenders}

It is worth mentioning that coatings cannot fully counterbalance the lack of the required creepage distance. If the later is not sufficient then the use of elastomeric creepage extenders is obligatory. These extenders can be applied in any insulator type. But they must be specifically designed for the considered insulator geometry, something that limits the possibility of a large scale application and further corresponds to an increased application cost. Therefore it is a method usually adopted in special conditions, when the methods already mentioned are not sufficient.

\section{APPLICATION OF RTV SIR COATINGS - THE CASE OF LINOPERAMA SUBSTATION}

The first application of RTV SIR Coatings in Crete started in 1998 at Linoperamata $150 \mathrm{kV}$ step up substation, which was fully coated a few years later. The $150 \mathrm{kV}$ Transmission Substation of Linoperamata is located in the west side of the city of Herakleion, right next to the sea coast. The substation suffers from intense marine pollution and the substation's insulators had to be washed at least twice in each summer in order to avoid flashovers. Live washing is prohibited by law in Greece, and therefore the substation had to be washed in two parts. The economical profit of RTV SIR coating application instead of washing, has proved rather significant [12]. In addition, more substations were coated and today, twelve years later, more than $6000 \mathrm{~kg}$ have been installed in $66 \mathrm{kV}$ and $150 \mathrm{kV}$ substations, in Crete and Rhodes, as illustrated in Figure 3.

Since application, surface activity has been remarkably suppressed and no flashovers have been experienced, although washing procedures have been suspended. Hence, RTV SIR coating application is considered rather successful. However, as the material age, concerns regarding the material reliability, evaluation and the necessary maintenance actions arise. Therefore, a leakage current monitoring system was installed in the Linoperamata Substation to monitor and investigate field performance of insulators.

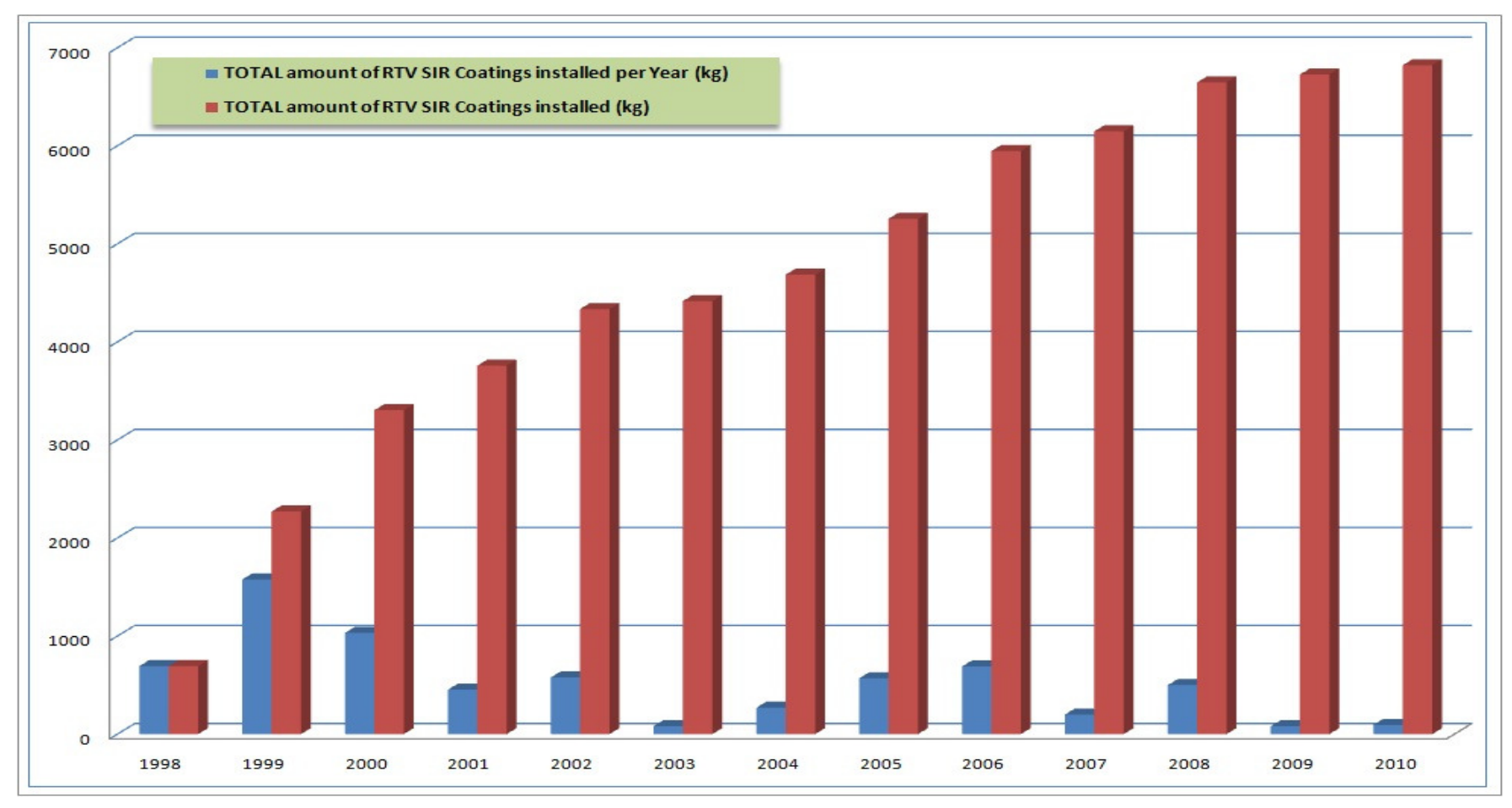

Figure 3. Amount of installed RTV SIR Coatings per year in Crete, Greece 


\section{LEAKAGE CURRENT MEASUREMENTS AND INSULATORS PERFORMANCE}

In service conditions, the coatings evaluation was based mainly on empirical observations, such as surface discharges noise and visual observation. In order to monitor field performance, a leakage current monitoring system has been installed in Linoperamata Substation. A collection ring is placed at the bottom of each monitored insulator and the collected leakage current is driven through a Hall sensor. A commercially available Data Acquisition system calculates and stores several leakage current related values. More details about leakage current monitoring in Linoperamata Substation can be found in $[17,19]$. A representation of the measuring system is shown in Figure 4a an actual photo of an installed collection ring is shown in Figure 4b.
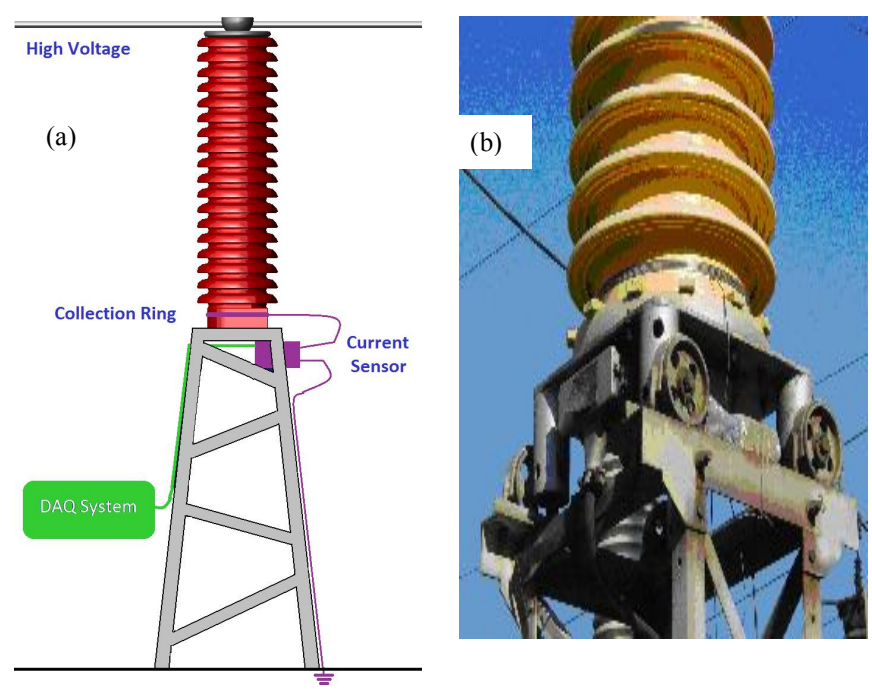

Figure 4. (a) Leakage current measurement system setup, (b) installation of the current collection ring on a $150 \mathrm{kV}$ RTV SIR coated voltage transformer.

Leakage current measurements verified the improvement achieved by the application of RTV SIR coatings. The monthly distribution of the accumulated charge recorded over a 5-year period on the surface of the monitored insulators is shown in Figure 5. All monitored insulators were $150 \mathrm{kV}$ post insulators of the same geometry, installed at the same location. The measurements concerning uncoated porcelain insulators are portrayed in Figure 5a and the measurements concerning porcelain RTV SIR coated insulators are portrayed in Figure $5 \mathrm{~b}$. The improvement achieved in the latter case is evident.

In addition, it is worth noticing that the period of activity is different in each case. In the case of uncoated porcelain insulators, surface activity is observed during the summer period and especially from August to October, as expected. In the case of RTV SIR Coatings the surface activity is increased during the winter and especially from November to March, although the main pollution problem is experienced during the summer. This behaviour has been correlated to the influence of different wetting mechanisms. During the summer, the main wetting mechanism present is condensation whereas during the winter is precipitation.
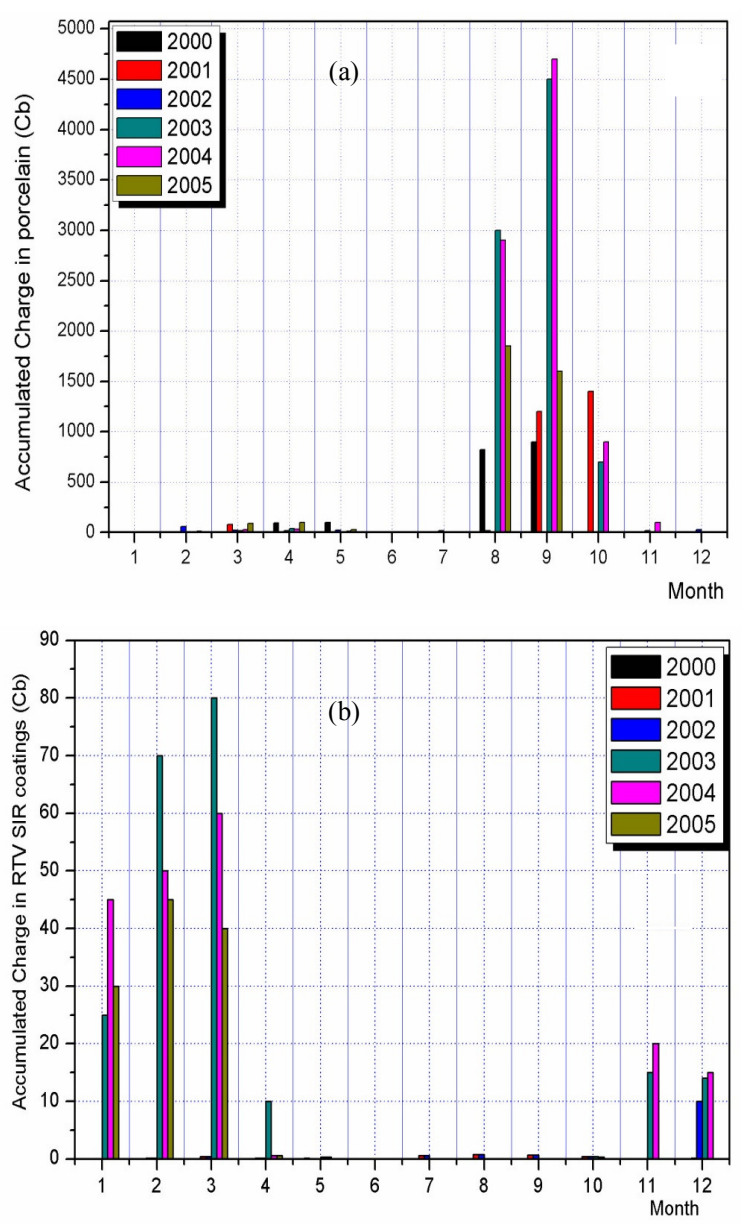

Figure 5. Accumulated charge for the same time period in the case of $150 \mathrm{kV}$ post insulators of identical geometry, installed at the same location (a) In the case of porcelain and (b) in the case of RTV SIR coated porcelain

A typical example of the influence of the two mechanisms on the two different insulation surfaces is shown in Figure 6 and Figure 7, illustrating an incident where both wetting mechanisms are present. Both insulators can be considered, originally, having the same contamination on their surface, since they are installed in the same place. As it can be seen in Figure 6, in the case of condensation (high relative humidity), activity is observed only on the porcelain insulator, a fact that is attributed to the hydrophobic surface of the RTV SIR coated insulators that prohibits the formation of conductive films.

On the other hand, surface activity is initially present on both insulators during rain (high precipitation). The effect of rain can be seen more clearly after a zoom-in, as portrayed in Figure 7. At the first incident of rain the activity on the coated insulator is considerably less than that on the porcelain. At the second incident of rain, however, the activity on the porcelain insulator has decreased whereas the activity on the coated insulator has slightly increased. However, the activity recorded 
on RTV SIR coated insulator was significantly lower in any case compared to the activity on the porcelain insulator. Finally, at the third incident, activity is not present on either insulator. It is evident that the cleaning effect of rain is different in each case. The first incident of rain was able to remove an amount of contamination from the porcelain insulator and the levels of activity decreased. On the other hand, the levels of activity on the RTV SIR coated slightly increased, which indicates that the same amount of rain could not clean the RTV SIR surface effectively. On the contrary, it seemed to favor the development of surface activity, which means that temporary hydrophobicity loss probably occurred. As the rain activity increased, both insulators were finally cleaned and therefore no surface activity was observed at the third incident.
In conclusion, it is shown that wetting mechanisms have different effects on each insulator. Considerable activity can be observed on porcelain insulators in the presence of condensation, but not on RTV SIR coated insulators. On the other hand, RTV SIR coated insulators acquire higher precipitation to be cleaned, in comparison with porcelain insulators, and favor the development of surface activity during light rain. In any case, however, the experienced activity is significantly smaller in the case of RTV SIR coated insulators. The effect of light rain explains the increased activity recorded on RTV SIR coated insulators from November to March since light rain is rather usual in Crete during the winter.

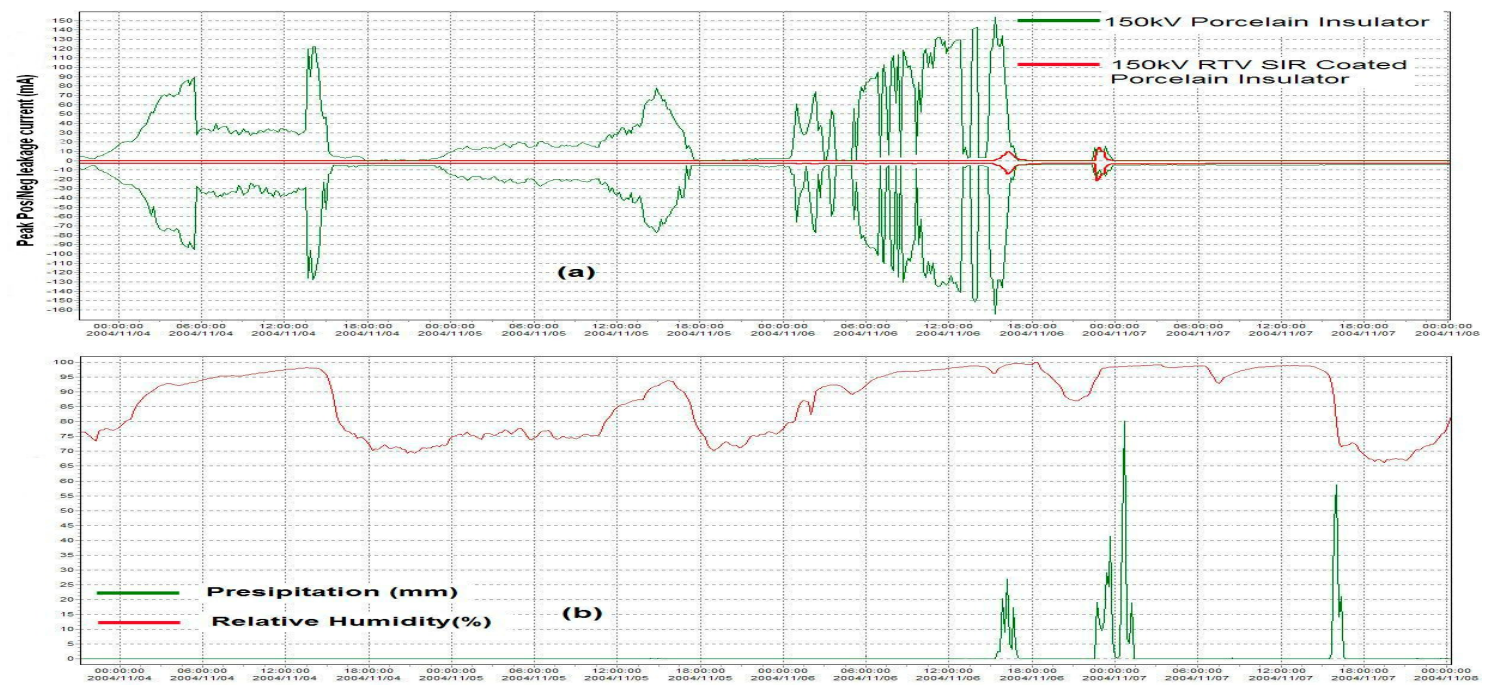

Figure 6. The impact of condensation and light rain on the surface behavior of both surface types (coated and not) in the case of two identical insulators, at the same place and time:(a) simultaneous measurements of the maximum and minimum surface leakage current observed on both insulators, (b) precipitation and relative humidity at the same place and time

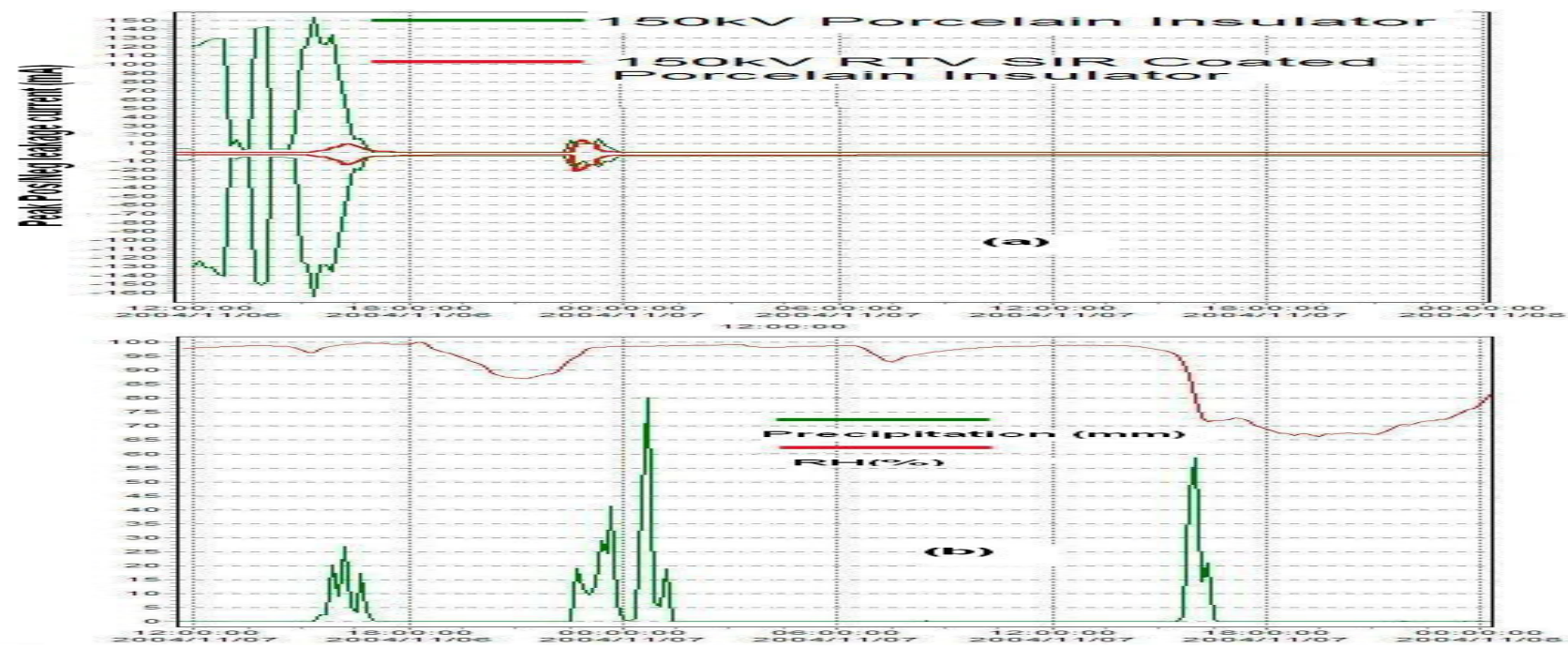

Figure 7. An enhanced (zoomed-in) version of Figure 6. (a) simultaneous measurements of the maximum and minimum surface leakage current observed on both insulators, (b) precipitation and relative humidity 


\section{CONCLUSIONS}

Pollution maintenance of high voltage substations is an issue for every utility worldwide. The case of substations is rather complex due to the service features and the corresponding financial cost of the equipment included in such installations. Several methods can be applied to cope with the problem in the design stage of new installations. The development of enclosed installations and especially GIS can be considered as the optimum solution as far as pollution is concerned. In the case of already installed equipment, the employed remedies have to improve the performance of the existing insulation, since the cost of replacement is considerable. Many methods can be employed in this direction. Insulator cleaning and especially high pressure water washing are the first to consider. However, they both are time and money consuming and the selection of the appropriate cleaning time is still an issue. On the other hand, RTV SIR Coatings provide a cost effective predictive remedy combined with long lifetime. In Crete, a large scale application has taken place and coatings that exceed a service period of 10 years are still in operation. The results from leakage current monitoring implemented on post insulators installed in a $150 \mathrm{kV}$ Substation indicate that coated insulators exhibit a much improved performance compared to non coated ones. Further, the period of activity in the case of coated insulators was found different, due to the interaction of the hydrophobic coating surface to the present wetting mechanisms and especially light rain.

\section{REFERENCES}

[1] R.E. Brown, T.M. Taylor, "Modeling the impact of substations on distribution reliability", IEEE Transactions on Power Systems, Vol 14, No 1, February 1999

[2] CIGRE WG 33-04, TF 01, "A Review of current knowledge: Polluted Insulators", Cigre Publications, 1998

[3] IEEE Std 957-1987, IEEE Guide for Cleaning Insulators

[4] J.S.T. Looms, "Insulators for high voltage", IEE Power Engineering Series 7.

[5] Wankowicz J.G., Gubanski S.M., Lampe, W.D., "Loss and recovery of hydrophobicity on RTV coating surfaces", IEEE Transactions on Dielectrics and Electrical Insulation, Vol 1, No 4, August 1994

[6] H. Hillborg, U.W. Gedde, "Hydrophobicity recovery of polydimethylsiloxane after exposure to corona discharges", Polymer, Volume 39, Issue 10, May 1998,

[7] Kim J., Chaudhury M.K., Owen M.J., "Hydrophobicity loss and recovery of silicone HV insulation", IEEE Transactions on Dielectrics and Electrical Insulation, Vol 6, No 5, October 1999

[8] Kim S.H., Cherney E.A., Hackam R., "The loss and recovery of hydrophobicity of RTV silicone rubber insulator coatings", IEEE Transactions on Power Delivery, Vol 5, No 3, July 1990

[9] D.P. Agoris, K.G. Siderakis, E.J. Thalassinakis, "Influence of the environment to the pollution performance of RTV Silicone Rubber coatings in Crete", 13th ISH, Netherlands 2003

[10] E. Thalassinakis, J. Stefanakis, K. Siderakis, D. Agoris, "Measures and Techniques against Pollution in the Cretan Transmission System", European Power and Energy Systems, IASTED, Crete, GREECE, 2002

[11] K. Siderakis, D. Agoris, J. Stefanakis, E. Thalassinakis, "Influence of the profile on the performance of porcelain insulators installed in coastal high voltage networks in the case of condensation wetting", IEE Proceedings on Science, Measurements and Technology, Vol 153, Issue 4, July 2006
[12] E. Thalassinakis, K. Siderakis, D. Agoris, "Experience with new solutions to combat marine pollution in the power system of the Greek islands", World Conf. on Insulators, Arresters and Bushings, Malaga, Spain, 2003

[13] R.S. Gorur, E.A. Cherney, J.T.Burnham, Outdoor Insulators, R.S.Gorur Inc, Phoenix, Arizona, USA

[14] IEEE Std 1523 - 2002, IEEE Guide for the application, maintenance and evaluation of RTV SIR Coatings for outdoor ceramic insulators, IEEE Outdoor Service Environment Committee, 2002

[15] E.A. Cherney, R.S. Gorur, "RTV SIR Coatings for Outdoor Insulators", IEEE Transactions on Dielectrics and Electrical Insulation, Vol 6, No 5, October 1999

[16] E.A. Cherney, "RTV Silicone - A high tech solution for a dirty insulator problem", IEEE Electrical insulation Magazine, Vol. 11, No. 6, November/December 1995

[17] K. Siderakis, D. Agoris, "Performance of RTV silicone rubber coatings installed in coastal systems", Electric Power Systems Research, Vol. 78, Issue 2, February 2008

[18] F. Pratomosiwi, Suwarno, "Performance Improvement of the Ceramic Outdoor Insulators Located at Highly Polluted Environment Using Room Temperature Vulcanized Silicone Rubber", International Journal of Electrical Engineering and Informatics, Vol. 2, No. 1, 2010

[19] D. Pylarinos, K. Siderakis, E. Pyrgioti, E. Thalassinakis, I. Vitellas, "Impact of Noise Related Waveforms on Long Term Field Leakage Current Measurements", IEEE Transactions on Dielectrics and Electrical Insulation, Vol. 18, No. 1, 2011

\section{AUTHORS PROFILE}

Kiriakos Siderakis received a diploma degree in Electrical and Computer Engineering in 2000 and a PhD Degree in 2006 from the University of Patras. Presently, he is working as a consultant with Public Power Corporation in Crete and also teaches High Voltage Engineering at the Technical Institute of Crete. His research activities include high voltage insulation, composite materials and performance of insulators in polluted areas. Dr Siderakis is a member of CIGRE and the Technical Chamber of Greece.

Dionisios Pylarinos received a Diploma in Electrical and Computer Engineering from the University of Patras in 2007. Presently he is with the High Voltage Laboratory of the School of Electrical and Computer Engineering at the University Of Patras. He has worked as a scientific consultant for PPC. His research interests include outdoor insulation, electrical discharges, high voltage measurements and high voltage equipment diagnostics and reliability.

Emmanuel Thalassinakis received his Diploma in electrical and mechanical engineering and also a $\mathrm{Ph} . \mathrm{D}$ degree from National Technical University of Athens. After working for the Ministry of the Environment, in 1991 he joined the Public Power Corporation where he is now Head of the Crete and Rhodes Sector of the Islands Network Operations Department. His professional and research interests are reliability, high voltage transmission technology, power system operation and contamination of insulators. Dr. Thalassinakis is a member of the Technical Chamber of Greece, IEEE and CIGRE.

Isidoros Vitellas is Director of the Islands Network Operations Department in PPC (Public Power Corporation) Athens, Greece. He was born in 1954 in Greece and has obtained an Diploma in Electrical Engineering and a PhD in the same field. His research interests include electrical power generation and transfer, degradation and breakdown of insulating materials, electromagnetics.

Eleftheria Pyrgioti was born in 1958 in Greece. She received her Diploma degree in electrical engineering from Patras University in 1981 and the Ph.D. degree from the same University in 1991. She is an assistant professor at the department of Electrical and Computer Engineering at the University of Patras. Her research activity is directed to high voltage, lightning protection, insulation coordination and distributed generation. 